\title{
Роль Я-релевантной информации в формировании представлений субъекта о себе
}

\author{
Кирилл В. Злоказов ${ }^{1}$, Николай И. Леонов ${ }^{2 *}$, Роман Ю. Порозов ${ }^{3}$ \\ ${ }^{1}$ Санкт-Петербургский университет Министерства внутренних дел Российской \\ Федерации, г. Санкт-Петербург, Российская Федерация \\ 2 Удмуртский государственный университет, г. Ижевск, Российская Федерация \\ ${ }^{3}$ Уральский государственный педагогический университет, г. Екатеринбург, Российская \\ Федерация \\ ${ }^{*}$ E-mail: nileonov@mail.ru
}

\begin{abstract}
Аннотация
Ввеление. Статья посвящена обсужАению роли Я-релевантной инорормации в фрормировании представлений субъекта о себе. Я-релевантная информация определяется как виА социальной информации, солержащей сведения о субъекте: мнения о нем, оценки и отношение к нему окружающих. Рассматриваются концепции восприятия субъектом Я-релевантной инфоормации, обобщаются известные свойства Я-релевантной информации. Критическая оценка современных представлений показывает необходимость получения новых знаний об отношениях межАу я-релевантной инфоормацией и представлением субъекта о себе, в частности на русскоязычной выборке. Описывается организация и результаты эмпирического исследования, направленного на получение данных знаний.
\end{abstract}

Методы. Методом исслеАования выступает социально-психологический эксперимент. Методами сбора данных - стандартизированные самоотчеты и интервью, методами обработки - контент-анализ и повторный Аисперсионный анализ. Выборка исследования: $n=129$; средний возраст 19,3 года; $49 \%$ - мужчины.

Результаты. Установлено, что социальная инорормация распознается как Я-релевантная, если в ней содержатся: а) указания на субъекта в прямых или косвенных обращениях к нему; б) инфоормация, важная Аля выполнения Аействий, уАовлетворения потребностей; в) указания на социальные объекты, ассоциированные с субъектом. Определено, что Я-релевантная информация влияет на самооценку и точность представлений субъекта о себе. Выявлено, что негативная я-релевантная информация побужАает субъекта к поиску новой социальной информации, ее верификации путем социального сравнения.

ОбсужАение результатов. Новизна ИсслеАОвания заключается в уточнении преАставлений о восприятии Я-релевантной информации на русскоязычной выборке. Определено влияние Я-релевантной информации на искажение знаний субъекта о себе. Установлены критерии, используемые субъектом Аля селекции информации 
на Я-релевантную и нерелевантную. Результаты могут использоваться Аля исслеАОваний трансорормаций социальной иАентичности участников интернет-сообществ, оценки угроз интернет-коммуникации разновозрастных групп населения.

\section{КАючевые слова}

представление о себе, образ Я, самооценка, социальное взаимолействие, я-релевантная инорормация, негативное самопредставление, трансорормация представлений о себе, социальная перцепция, самопознание, социальное поведение

\section{Основные положения}

- я-релевантная инорормация - разновидность социальной инфоормации, сообщающей субьекту мнения и оценки окружающих;

- я-релевантная инорормация влияет на самооценку, самоотношение и преАставления субъекта о себе;

- Я-релевантная информация, не соответствующая представлениям субъекта о себе, стимулирует социально-перцептивную активность субъекта.

\section{Для цитирования}

Злоказов К. В., Леонов Н. И., Порозов Р. Ю. Роль Я-релевантной информации в формировании представлений субъекта о себе // Российский психологический журнал. 2018. T. 15, № 4. C. 70-96. DOI: 10.21702/rpj.2018.4.4

Материалы статьи получены 28.08.2018

UDC 316.614.5:159.9.072.43

DOI: $10.21702 /$ rpj.2018.4.4

\section{The Role of Self-Relevant Information in Individuals' Representations of the Self}

\section{Kirill V. Zlokazov', Nikolai I. Leonov ${ }^{2 *}$, Roman Yu. Porozov ${ }^{3}$}

${ }^{1}$ Saint Petersburg University of the Ministry of Internal Affairs of the Russian Federation, St. Petersburg, Russian Federation

2 Udmurt State University, Izhevsk, Russian Federation

${ }^{3}$ Ural State Pedagogical University, Ekaterinburg, Russian Federation

${ }^{*}$ Corresponding author. E-mail: nileonov@mail.ru

\section{Abstract}

Introduction. This paper discusses the role of self-relevant information in individuals' representations of the self. Self-relevant information is defined here as a type of social 
information that contains such data about an individual as other people's opinions, judgements, and attitudes about that person. Critical assessment of the existing knowledge on the relationship between self-relevant information and individuals' representations of the self shows its insufficiency, especially concerning Russian samples. This paper: (a) considers various concepts of individuals' perception of self-relevant information, (b) focuses on the known properties of self-relevant information, and (c) describes the procedure and results of an empirical study of the relationship between self-relevant information and individuals' representations of the self.

Methods. The authors undertook a socio-psychological experiment that employed standardized self-reports and interviews as the means for data collection. Content analysis and repeated measures ANOVA were the data processing methods. The sample consisted of 129 individual participants with a mean age of 19.3 years, $49 \%$ of whom were men.

Results. The respondents perceived social information as self-relevant if it contained a) direct or indirect reference to them; b) information important for their actions and meeting their needs; and c) references to social objects associated with them. The study showed that self-relevant information affects individuals' self-appraisal and the accuracy of their representations of the self. Negative self-relevant information encourages individuals to seek new social information and to verify it by social comparison.

Discussion. This study, carried out on the Russian sample, enriches our knowledge of individuals' perception of self-relevant information and our understanding of how selfrelevant information may lead to distorting individuals' representations of the self. The findings offer some criteria for distinguishing self-relevant information from the irrelevant one. The results can be used to further study social identity transformations among participants of Internet communities and to assess threats of online communications in different age groups.

\section{Keywords}

self-representation, self-image, self-appraisal, social interaction, self-relevant information, negative self-representation, transformation of self-representations, social perception, self-knowledge, social behavior

\section{Highlights}

- Self-relevant information is a kind of social information that apprises individuals about opinions and judgments of those around them.

- Self-relevant information affects individuals' self-appraisal, self-perception, and self-representation.

- Self-relevant information that does not correspond to individuals' representations of the self stimulates their socio-cognitive activity. 


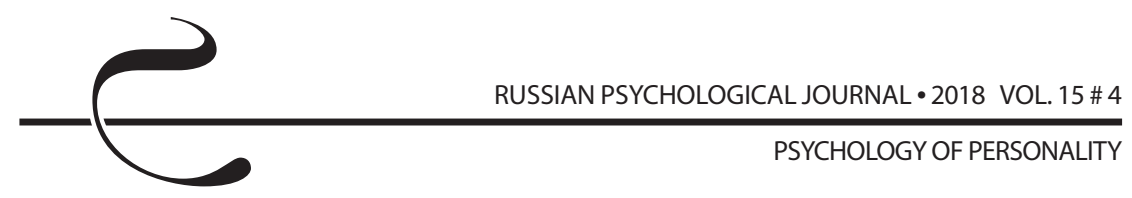

\section{For citation}

Zlokazov K. V., Leonov N. I., Porozov R. Yu. The Role of Self-Relevant Information in Individuals' Representations of the Self. Rossiiskii psikhologicheskii zhurnal - Russian Psychological Journal, 2018, V. 15, no. 4, pp. 70-96 (in Russian). DOI: 10.21702/rpj.2018.4.4

Original manuscript received 28.08.2018

\section{Введение}

Влияние социального окружения на становление и изменение представлений о себе является одним из интересных вопросов, ждущих своего окончательного научного разрешения. Важность его изучения определяется ролью субъективных представлений в деятельности и отношениях с окружающими. Адекватные представления способствуют правильным решениям, верным поступкам, а искаженные - делают планы недостижимыми, приводят к просчетам и ошибкам, ухудшают отношения с окружающими [1]. Понимание механизма формирования представлений позволяет корректировать их, избегая последствий несоответствующих реальности самоотношения и самомнения.

В современной социальной психологии представление субъекта о себе ставится в зависимость от социального окружения. Следуя идее социального конструкционизма, то, каким видит себя субъект, что он знает о себе и как оценивает себя, не только возникает, но и меняется в социальном взаимодействии [2]. При этом социальное окружение не только побуждает, но и предлагает средства для множества трансформаций, которые претерпевает представление о себе. Как уверяют социальные философы, представление субъекта о себе опосредовано социальным окружением в языковом и ролевом, семантическом и ценностном контекстах [3]. Несмотря на аргументацию влияния на представления в глобальном виде, вопрос о трансформации представлений остается открытым в его краткосрочном периоде. Что изменяет представление субъекта о себе в рутинном, повседневном взаимодействии? Что выступает средством для изменения, и каким образом оно осуществляется?

В статье рассматривается один из источников формирования и трансформации представлений субъекта о себе - Я-релевантная информация. Структура статьи отражает последовательность и логику изложения, включает введение, теоретическую и эмпирическую части, обсуждение результатов и общее заключение.

Для описания влияния Я-релевантной информации авторы обращаются к современным концепциям представлений субъекта о себе. Посредством их обобщения выявляется специфическая роль социальной информации в организации структуры представлений субъекта и их содержания. Выясняется, 
что субъект чувствителен к информации, содержащей мнения и оценки окружающих относительно его самого и его действий. Благодаря получению данной информации субъект уточняет либо преобразует собственное представление о себе. Однако особенность социальной информации заключается в ее неоднородности и, как следствие, необходимости выполнения соотношения ее содержания с представлениями субъекта. Изучению вопросов о субъективных критериях выделения Я-релевантной информации, оценке ее влияния на представления субъекта о себе, стратегии поиска информации при наличии ее искажений посвящена эмпирическая часть статьи.

\section{теоретическое введение}

Взгляды современной социальной науки на трансформацию представлений субъекта о себе многомерны: известны философские (K. Gergen [4]), социологические (R. Leary [5]) и культурологические (S. Kitayma [6]) подходы к их исследованию. В психологических исследованиях изменение представлений изучается преимущественно на основе когнитивного подхода. В соответствии с ним, представление субъекта о себе определяется информацией, поступающей из окружающего мира - социальной информацией. Формирование представлений ставится в зависимость от различных факторов: нейрофизиологической организации памяти [7], стратегий мышления [8], особенностей возрастного развития [9], социально-культурных условий [10].

Вместе с тем во всех концепциях социальная информация представляется необходимым условием образования и изменения представлений субъекта. Однако ее роль в формировании представлений определяется по-разному. Влияние социальной информации на представление субъекта условно можно описать посредством двух различающихся моделей: директивной и опосредованной.

В директивной модели информация не анализируется субъектом, а сразу ложится в основу его самооценки, дополняет или уточняет знание о себе. Подобная ситуация возникает в отношениях между родителями и детьми, учителями и учениками, консультантом (ментором) и консультируемым и иных контекстах, в которых субъект считает собеседника важной персоной, а его мнение о себе представляет точным и надежным. Эмпирические исследования директивной модели воздействия подтверждают влияние информации на самооценку и модели поведения.

В опосредованной модели социальная информация анализируется и интерпретируется субъектом. Соответственно, субъект оценивает необходимость, целесообразность ее применения. Как правило, социальная информация используется для планирования, принятия решения, сознательной коррекции поведения, а ее влияние на самооценку и знание о себе определяется 
отношением к ней субъекта. Моделью опосредованного типа описываются разновидности социального взаимодействия, в которых информация используется субъектом для регуляции представлений о себе и самооценки.

Рассмотренные модели представляют закономерности отношений между социальным окружением и субъективными представлениями. В них раскрывается внешняя сторона отношений субъекта с социальным окружением, образующая процесс получения социальной информации и ее восприятия. Под другим углом зрения влияние социальной информации рассматривают концепции организации представлений субъекта о себе. Они уделяют больше внимания структуре представлений субъекта о себе, считая организацию представлений основным фактором изменений, а социальную информацию дополнительным, выступающим в качестве ресурса.

\section{Влияние социальной информации на представление субъекта о себе}

Вопрос формирования представлений о себе для социальной психологии не является новым. В основании его разработки лежат идеи У. Джемса о соотношении Я-реального и Я-социального, взгляды Ч. Кули о влиянии общества на самооценку субъекта и его знание о себе, описанная Л. Фестингером роль несоответствий между представлениями субъекта и социальной информацией. В этих работах определены основания современных взглядов на представления субъекта о себе. Конечно, современное воплощение этих идей отличается от изначальных представлений. Концептуальные взгляды на образ Я усложняются. На смену гомогенным моделям приходят гетерогенные, в которых образ Я имеет сложную структуру (например, «индивидуальное и коллективное измерения Я», предложенные Н. C. Triandis [11]). Статические модели заменяются динамическими, точнее характеризующими формирование представлений о себе [12], определяются детерминационные отношения между субъектными и социальными основаниями представлений субъекта о себе [13], вводятся имплицитные и эксплицитные факторы, опосредующие формирование образа Я $[14,15]$. В целом, разработка классических идей приводит к появлению новых объяснительных моделей, сложных по своей структуре и функциональным отношениям, но более адекватных процессам формирования представлений субъекта о себе. Накопление знаний приводит к расширению предметных областей исследования, представлений и появлению самостоятельных направлений.

Появляются концепции, показывающие роль социальной информации в становлении представлений субъекта о себе. В большинстве все они относятся к социально-когнитивной парадигме, считающей социальную информацию ключевым условием развития субъекта. Данные концепции являются неоднородными - при общем объекте исследования их теоретические предпосылки 
вытекают из разных социальных наук, а положения и инструментарий исследования методологически несопоставимы друг с другом. Этим объясняется своеобразный «параллелизм» взглядов на природу представлений субъекта, приводящий к существованию различных предметных областей. Фактически внутри когнитивной парадигмы существуют три области исследования, образованные нейрофизиологическими, социологическими и социально-психологическими подходами. Рассмотрим их более подробно.

Представление о себе, определенное организацией памяти. Данная концепция разрабатывается на основе нейрофизиологических исследований памяти. В них процессы памяти представляются ключевым условием существования субъекта, поскольку именно память хранит все знание субъекта о себе. Соответственно, представление о себе формируется на основе механизмов памяти, запечатлевающих и воспроизводящих любую разновидность информации о субъекте. В данных исследованиях показано, что знание субъекта о себе воплощается средствами двигательной, образной, символической и иных видов памяти.

Механизмы, участвующие в работе с разными видами информации, независимы друг от друга и, в то же время, не являются специфическими, поскольку обеспечивают сохранение любой воспринимаемой субъектом информации. По мнению J. F. Kihlstrom и N. Cantor, представление о себе образовано двумя видами знания о себе - семантическим и эпизодическим [16]. Семантическое знание является целостным, основывается на осмыслении субъектом своих уникальных, ключевых характеристик. Эпизодическое знание дискретно, оно состоит из воспоминаний о событиях, поступках, ярких эмоциональных переживаниях и других разобщенных, но связанных с субъектом элементах жизненного опыта.

Семантическая и эпизодическая информация накапливается посредством работы памяти в течение всей жизни. Представление субъекта о себе изменяется и модифицируется при получении новой информации или размышлении над прошлым опытом. Нейропсихологические исследования субъективных представлений о себе, проведенные S. B. Klein, определили виды знания о себе, необходимые для формирования комплексного представления о себе [17]. Ими являются: воспоминания об отдельных эпизодах собственной жизни; представления о своих личностных особенностях и чертах; знание субъектом конкретных фактов своей жизни; представление о временной протяженности собственной жизни - факты о Я в разные временные промежутки; представление о собственном авторстве и участии в различных социальных событиях; способность к саморефлексии, выраженная в возможности объяснять свои действия социально-приемлемым способом. Нарушения и дефекты памяти, как показывают клинические исследования, сказываются на полноте и согласованности самопредставлений [18]. 
Представление о себе как схема Я. Данная концепция базируется на идее обобщения субъектом своих ключевых атрибутов (черт, свойств, установок, моделей поведения) в виде схемы (когнитивной структуры), сохранении ее в памяти и использовании в повседневной жизни [19]. Субъект схематизирует представление о себе, анализируя свой опыт, оценки и суждения окружающих. Эмпирически зафиксированы схематические описания, соотносящие представление о своем теле, себе в общении с другими людьми, себе в учебе, труде, спорте и пр. Кроме того, к схемам относят представление субъекта о себе в будущем - ожидаемом (потенциальном) состоянии. Самооценка в рамках данной концепции также рассматривается в виде схемы.

Глобальная схема, определяющая общее представление субъекта о себе, основывается на трех типах знания: семантическом (абстрактном обобщении «Кто Я есть?»), занимающем вершину представления и задающем дальнейшую организацию всей информации о себе; эпизодическом (автобиографических представлениях о себе, располагающихся в основании представления); процедурном - воспоминаниях о своих способностях, навыках, достигнутых целях в различных областях социального взаимодействия: учебе, работе и пр.

Схематизированные представления о себе рассматриваются составляющими частями глобальной Я-концепции субъекта. Способность к схематизации считается когнитивным навыком, которым субъект либо обладает, либо обучается. Количество схематических представлений у субъекта, по мнению представителей этого подхода, индивидуально и очень сильно варьируется. По модальности схемы делятся на позитивные и негативные. Функционально схемы упрощают поведение, ускоряют обработку информации, повышают готовность к типичным действиям, но затрудняют адаптацию к быстро меняющимся условиям [20]. Субъект сравнивает имеющиеся представления с социальной информацией, оценивая, к какому из вариантов он приближается. В зависимости от результата сравнения субъект регулирует свою социальную активность.

Процесс формирования, уточнения или изменения схемы обусловлен поступающей социальной информацией. Так, оценка коллег заставляет сотрудника, считающего себя опытным водителем, анализировать стиль своего вождения. Кроме того, актуализированные схемы регулируют перцепцию данной информации. Например, отличник, ожидающий положительной оценки, будет дольше воспринимать информацию о плохой оценке, сомневаться и не доверять ей, чем известию о хорошей оценке. Наконец, изменение схем из-за социальной информации влияет на социальное поведение. Противоречащая информация замедляет темп и снижает качество, а согласующая - напротив, повышает темп и эффективность.

Парциальные и интегральные концепции представлений о себе. Данная 
группа концепций базируется на идеях социального интеракционизма, подчиняющих самосознание субъекта влиянию структур и институтов общества. Разрабатываемые на его основе концепции можно разделить на группы, исходя из характера использования социальной информации для организации Я - парциальные и интегративные.

Парциальные концепции предполагают, что источники социальной информации формируют изолированные, несвязанные представления субъекта о себе. Например, подросток в ходе дворового футбольного матча получает информацию о своих вратарских способностях. Эта информация не влияет на другие его представления о себе и забывается за пределами футбольного поля. Таким образом, представления субъекта о себе отделены друг от друга и актуализируются в ходе социальных отношений. Соответственно, самопредставление зависит от источников социальной информации - родителей, братьев и сестер, других членов семьи, близких друзей и коллег. Их взгляды, оценки, а также сравнения с ними выступают основанием для определения себя и самоописания. Ряд эмпирических исследований подтверждает положения парциальных концепций. К примеру, люди часто не отличают свое мнение от мнения окружающих, приписывают себе качества людей из своего окружения [21]. Нередко представление о себе выражается терминами межличностных качеств (общительный, дружелюбный, честный), т. е. воспроизводит оценки окружающих. Наконец, социальный характер самопредставлений прослеживается через неосознанное указание на близость и наличие отношения принадлежности «мнение моих родителей...», «мой руководитель говорит», «мои друзья считают» [22].

В парциальных концепциях социальные категории и описания трансформируются в знания субъекта о себе путем «встраивания» или дополнения уже имеющегося представления новым. Интегративные концепции построены на идее о том, что субъект обобщает социальную информацию для построения комплексного и целостного представления о себе. К примеру, A. R. McConnell определяет представление о себе разнородным по содержанию и зависимым от контекста социальных отношений [23]. По его мнению, субъекты определяют себя, используя множество источников информации - социальные ситуации, отношения с другими людьми, роли, социальные оценки своего поведения и т.д. Данная информация не является согласованной и, к примеру, получив задачу на самоопределение, субъект обозначает себя несоотносимыми, по мнению источников данных понятий, категориями. Снижение противоречий обеспечивается зависимостью самопредставлений от социального контекста - в разных ситуациях задействуются согласованные представления о себе. Таким образом, часть представлений субъекта о себе изменяется тогда, когда он находится в определенном социальном окружении. 
В контексте интегративного подхода объяснение отсутствия конфликта между различающимися по содержанию представлениями осуществляется посредством идеи об уровнях их организации. Так, иерархическая организация представлений субъекта определяется тремя контекстами социального взаимодействия - внутриличностным, межличностным и коллективным [24]. Субъект объединяет получаемую от них информацию таким образом, чтобы в совокупности разнородного знания вычленить собственную уникальность. Соответственно, в рамках интегративного подхода информация подвергается фильтрации и переработке самим субъектом, стремящимся снизить ее противоречивость.

В целом интегративный подход, в сравнении с парциальными моделями, обладает определенным эвристическим потенциалом. К примеру, он объясняет разнообразие представлений о себе у субъектов, оказывающихся в гомогенных социальных условиях, не допускающих индивидуализации поведения (работники, чьи трудовые функции детально регламентированы, военнослужащие и пр.). В моделях парциального типа данное невозможно, поскольку они устанавливают прямые отношения между социальными условиями и самоопределением субъекта.

Проведенный анализ концепций формирования представлений субъекта о себе позволяет сделать некоторые выводы о роли социальной информации.

Механизмы переработки и сохранения социальной информации определяют организацию представлений субъекта о себе, задавая их специфическую иерархию. Семантические, т. е. подвергнутые осмыслению, представления о себе занимают высший уровень, фактологические и автобиографические низший. Знание о себе формируется в процессе обобщения социальной информации, представление о себе воспроизводится в социальных понятиях, раскрывающих черты, свойства, навыки субъекта.

Новая социальная информация соотносится с имеющимися представлениями субъекта. При этом она может согласовываться с ними, а может противоречить. Представление субъекта строится на основе полученной информации. Оно сохраняет содержание информации, становясь противоречивым или недостаточно конкретным, если информация содержит неточности. Интерпретация социальной информации определяется свойствами субъекта: его индивидуальными особенностями (чертами личности и характера), жизненным опытом социального взаимодействия, социальными отношениями.

Все концепции учитывают роль информации в изменении представлений субъекта о себе, однако ее содержание не всегда становится предметом оценки. Указывается, что информация дополняет, преобразует или конфликтует с уже имеющимися представлениями. Однако информация не является однородной: какая-то содержит оценку решений и действий субъекта, сообщает 
об отношении окружающих, а другая - не содержит ее, либо не сообщает ничего нового. Целесообразно сфокусироваться на информации, содержащей знание, способствующее формированию представлений субъекта о себе.

\section{Я-релевантная информация}

Социальная информация, содержащая сведения о субъекте, обозначается как Я-релевантная (self-relevant). Воспринимая ее, субъект получает оценки и мнения окружающих людей о собственных действиях, решениях и поступках. Я-релевантная информация растворена в потоке коммуникации, поскольку в повседневном взаимодействии люди часто оценивают друг друга или выражают свое отношение. В определенных ситуациях Я-релевантная информация выделяется в качестве отдельного предмета коммуникации. Например, высказывания учителя школьнику содержат оценку его действий, характеристику проявленных им личностных свойств.

Научное представление о Я-релевантной информации достаточно однородно. Областями ее изучения выступают процессы социального взаимодействия в обучении и труде, творчестве и спортивном соперничестве, поведении потребителей. Во всех них она представляется средством воздействия на поведение субъекта, облегчающим обучение, достижение результатов. Близкими по смыслу понятиями выступают понятия «социальная оценка» и «обратная связь» (feedback) [25]. Как и оценка, обратная связь представляет вид информации, предназначенной субъекту и выражающей отношение окружающих [26]. При этом отличие Я-релевантной информации заключается в необходимости определения принадлежности (отношения) информации субъекту. Оценка, критика или обратная связь не требуют атрибуции релевантности, поскольку содержат указание на адресата. Вместе с тем безадресная социальная информация может восприниматься субъектом как релевантная.

Вне зависимости от ее адресации, субъект чувствителен к Я-релевантной информации. Как показывают эмпирические исследования, релевантная информация воспринимается быстрее и точнее нерелевантной [27], кроме того, она легче запоминается и воспроизводится [28].

Атрибуция релевантности зависит от способности субъекта осознавать информацию и связывать ее с собой [29]. В этом процессе большое значение имеют когнитивные способности субъекта, обеспечивающие восприятие информации, селекцию и интерпретацию. Эмпирически установлено, что скорость обработки Я-релевантной информации зависит от ее содержания, и, как указывают исследователи, соответствует U-образной кривой [30]. Центр кривой соответствует максимальной схожести информации с ожиданием, а ее края - расхождению. Соответственно, соответствующая представлениям субъекта информация обрабатывается медленнее, чем отличающаяся от них. 
Влияние на атрибуцию оказывает содержание информации (например, упоминание имени как указание на ее принадлежность субъекту), ясность доступность информации пониманию, источник информации, ситуация коммуникации, личностные особенности субъекта, а также другие факторы. В случае непонимания информации либо недооценки субъект может не отнести ее к себе, и, как следствие - не использовать. С другой стороны, частое приписывание информации, излишнее внимание к оценкам окружающих дезорганизуют деятельность субъекта.

Функционально Я-релевантная информация влияет на деятельность субъекта. Она мотивирует, регулирует, влияет на эффективность деятельности, подтверждает его представления о себе, расширяет и изменяет их. В исследованиях учебной, спортивной или профессиональной деятельности значение Я-релевантной информации раскрывается в самоуправлении активностью. Благодаря ей корректируются ошибки в действиях, устраняются расхождения между планируемыми целями и реальными результатами.

Подводя итоги анализа, отметим, что в современных социально-психологических исследованиях изучается влияние Я-релевантной информации на поведение и деятельность субъекта. Рассматриваются вопросы атрибуции информации, определяются стимулирующий и регулирующий эффекты воздействия информации на деятельность. Связь Я-релевантной информации с представлениями субъекта о себе рассматривается по отношению к отдельным видам представления - самоуважению, самооценке. К тому же, измерению подвергается не социально-перцептивный этап, а последствия воздействия: изменение самопредставлений, снижение самооценки и пр. Как следствие, знаниевый компонент Я-релевантных представлений не всегда оказывается предметом изучения, в отличие от самооценки или самоотношения.

Экспериментальные ситуации часто имеют ограничения, сказывающиеся на характере результатов. Например, изучается влияние информации, целенаправленно передаваемой субъекту, а не полученной им в результате собственной поисковой активности. Как следствие, неясными остаются механизмы атрибуции, показывающие селекцию информации субъектом.

В исследованиях зачастую задаются контексты получения информации, которыми выступают виды деятельности либо конкретные ситуации. В результате получаемая информация соотносится с отдельными представлениями о себе и связывается с конкретной социальной ролью. Как следствие, изучаются изолированные, контекстно-зависимые, а не глобальные представления.

В этой связи важным является восполнение пробелов в научном представлении об Я-релевантной информации. К их числу относятся - определение показателей, используемых субъектом при селекции социальной информации на релевантную и нерелевантную, выявление влияния 
Я-релевантной информации на знаниевую составляющую представлений субъекта о себе и, наконец, изучение последствий несоответствия Я-релевантной информации представлениям субъекта о себе.

Для решения данных вопросов нами было проведено исследование процесса восприятия и интерпретации Я-релевантной информации. Его результаты приводятся в данной статье.

\section{Методы}

Цель эмпирического исследования - изучение особенностей использования Я-релевантной информации при трансформации представлений субъекта о себе.

Гипотезами исследования выступили три предположения:

1) Я-релевантная информация извлекается из поступающей социальной информации благодаря содержанию в ней вербальных и невербальных указаний на субъекта;

2) Я-релевантная информация изменяет уровень самооценки, влияет на определенность знаний субъекта о себе;

3) несоответствие Я-релевантной информации представлениям субъекта о себе побуждает к поиску новой социальной информации.

Основным методом исследования выступал социально-психологический эксперимент. Посредством эксперимента изучались способы экспликации Я-релевантной информации, воздействие Я-релевантной информации на представление о себе, стратегии поиска Я-релевантной информации в ситуации ее несоответствия представлениям субъекта о себе.

Методами сбора данных выступали: специально разработанное интервью, опросник измерения самооценки Дембо - Рубинштейн в модификации А. М. Прихожан, опросник «Оценка представлений субъекта о себе» [31].

Методика «Оценка представлений субъекта о себе» является стандартизированным самоотчетом. Включает 33 утверждения, сгруппированные в четыре блока представлений субъекта о себе. Изучаются: а) представление об уникальности и отличии от окружающих; б) представление о компетентности и эффективности социального взаимодействия; в) представление о соответствии социальным ролям; г) представление о поддержке, помощи окружающих. Каждое утверждение имеет четыре варианта ответа. Выбор ответа осуществляется на основе оценки обследуемым определенности (ясности, конкретности) представления о себе. Оценивались показатели определенности/неопределенности представления субъекта о себе в каждом из описанных областей.

Методика Дембо - Рубинштейн является классической методикой измерения самооценки. Измерялись семь показателей самооценки. Их результаты приводились к одному значению, посредством усреднения. Для оценки самооценки использовалась шкала в диапазонах, приведенных 
по П. В. Яньшину «"чрезмерно высокая" - "чрезмерно низкая"» [32].

Интервью использовалось для сбора качественных данных о восприятии, переработке и поиске Я-релевантной информации. Оно включало вопросы в открытой форме. Вопросы были сгруппированы в три блока.

Первый блок: определение критериев селекции Я-релевантной информации. Задавались вопросы: «Как Вы поймете, что информация действительно о Вас? Что именно указывает на это?»; «Как другие люди поймут, что говорится о Вас»; «Какую информацию Вы всегда принимаете на свой счет?».

Второй блок. Влияние Я-релевантной информации о себе на представление о себе. Использовались вопросы: «Как на Вас влияет информация, несоответствующая Вашему мнению о себе?»; «Что Вы ощущаете, если получили негативную либо несоответствующую информацию о себе?»; «Какую информацию такого рода Вы переживаете чувствительнее всего?».

Третий блок. Последствия получения Я-релевантной информачии. Задавались вопросы: «Как Вы относитесь к информации о Вас, которую обсуждают друзья и коллеги?», «Если Вас считают не таким, каким Вы себя представляете, что обычно Вы предпринимаете?», «Как Вы считаете необходимым поступить с распространителем (источником) несоответствующей информации о Вас?».

Методы обработки. Результаты интервью обрабатывались методом контент-анализа. Высказывания реципиентов переводились в текстовый вид и кодировались, названные обследуемыми признаки Я-релевантной информации группировались в соответствии с единицами контент-анализа.

При проведении контент-анализа использовались четыре вида категорий. Первая категория, «вербальные указания на субъекта», включала лексические единицы, описывающие вербальные признаки: личные местоимения («меня», «мое», «мой», «моя» и пр.). Вторая категория, «невербальные указания на субъекта», обобщала поведенческие проявления лиц, взаимодействующих с субъектом («посмотрел на меня», «показал на меня» и пр.). Третья категория, «социальные характеристики субъекта», содержала указания на персональные данные субъекта (имя, фамилия, отчество, прозвище (никнейм), вид занятий, социальный статус). Четвертая категория, «внешние признаки», характеризовала характеристики внешности (особенности внешнего вида, телосложения и пр., которые субъект ассоциировал с собой).

Методы статистической обработки применялись при анализе различий между измерениями самооценки и представлений субъекта о себе. Использовался дисперсионный анализ повторных измерений (repeated measurement analysis of variance), a не t-критерий Стьюдента, поскольку изучалось различие дисперсий между представлениями о себе, подвергнувшихся воздействию Я-релевантной информации. 


\section{Ход эксперимента}

Эксперимент проводился индивидуально, в форме собеседования. Участнику исследования предлагалось заполнить бланки измерения уровня самооценки и опросника представлений о себе, затем объявлялась фабула эксперимента, и проводилось повторное измерение самооценки и представлений субъекта о себе посредством опроса. В завершение эксперимента проводилось интервью.

Фабулой эксперимента являлось сообщение о том, что кто-то распространяет личную информацию об участнике эксперимента. Факт распространения информации представлялся неточным, содержание информации участнику не раскрывалось. Показывалось лишь, что распространитель хорошо осведомлен, являясь, по-видимому, кем-то из числа друзей или знакомых. Подчеркивалось, что распространение информации может ухудшить представление окружающих об участнике. Обсуждались социальные последствия распространения искаженной информации.

После доведения информации каждого из участников интервьюировали в соответствии со специально разработанным набором вопросов. Интервью проводилось без ограничения времени на ответы.

Выборка исследования. В исследовании принимали участие студенты очной формы обучения, обучающиеся по программам психологического и юридического направления, уровень бакалавриата и специалитета; $\mathrm{n}=129$; средний возраст 19,3 года; $49 \%$ - мужчины.

\section{Результаты}

\section{Восприятие и извлечение субъектом Я-релевантной информации}

Посредством контент-анализа интервью были определены признаки, используемые для экспликации Я-релевантной информации. 89 \% признаков, свидетельствующих об отношении информации к субъекту, выступают как прямые указания на субъекта (например, «когда меня называют», «про меня говорят»), 8 \% - невербальные указания (например, «показал рукой», «кивает на меня»), 2 \% признаков содержат косвенные признаки субъекта (например, «называют по увлечению», «по одежде», «по группе»). В числе прямых описаний, наряду с указанием персональных данных (63\% опрошенных судят по присутствию имени, фамилии), фигурируют его идентификаторы в интернет-сообществах (22\% - «никнейм», «ник»).

Полученные результаты выходят за пределы поставленной гипотезы о релевантности информации, содержащей вербальные и невербальные указания на субъекта. Установлено, что социальная информация считается Я-релевантной, если она представляет ценность для субъекта. Ценность определяется степенью соответствия информации: состоянию субъекта (на что указывают 41 \% участников, например «понимаю, что как бы для 
меня говорят», «прислушиваюсь, если важно»); актуальной деятельности (33 \% - например, «когда я тем же занят», «как услышал, так и делаю»). Помимо этого, информация считается релевантной, если она сообщает об угрозе (18\% - например, «об опасности говорят», «информацию про погоду или пожар») либо близких людях, знакомых (6\%, например «про друзей говорят», «запоминаю, а потом подруге пересказываю»).

Влияние Я-релевантной информации на представления субъекта о себе измерялось посредством статистического сопоставления результатов измерений самооценки и представлений субъекта о себе до прочтения экспериментальной фабулы и после завершения ее обсуждения. Сведения об изменении этих показателей под влиянием Я-релевантной информации представлены в таблице 1.

Таблица 1. Изменение самооценки и субъективных представлений о себе поА влиянием Я-релевантной инорормации

Table 1. Influence of self-relevant information on changes in self-appraisal and self-concept

\begin{tabular}{|c|c|c|c|c|}
\hline \multirow[b]{2}{*}{$\begin{array}{c}\text { № } \pi / \Pi \\
\text { No. }\end{array}$} & \multirow[b]{2}{*}{$\begin{array}{c}\text { Измеряемые } \\
\text { показатели } \\
\text { Measured } \\
\text { characteristics }\end{array}$} & \multicolumn{2}{|c|}{$\begin{array}{c}\text { Количественные } \\
\text { характеристики } \\
\text { Quantitative characteristics }\end{array}$} & \multirow{2}{*}{$\begin{array}{c}\text { Значения } \\
\text { статис- } \\
\text { тической } \\
\text { оценки } \\
\text { размичий } \\
\text { Statistical } \\
\text { differences }\end{array}$} \\
\hline & & $\begin{array}{c}\text { Ао предъяв- } \\
\text { ления } \\
\text { информации } \\
\text { Before } \\
\text { presentation } \\
\text { of information }\end{array}$ & $\begin{array}{c}\text { После за- } \\
\text { вершения } \\
\text { предъявления } \\
\text { After pre- } \\
\text { sentation of } \\
\text { information }\end{array}$ & \\
\hline 1 & $\begin{array}{l}\text { Уровень самоо- } \\
\text { ценки (по Аембо- } \\
\text { Рубинштейн) } \\
\text { Level of self-ap- } \\
\text { praisal (in Dembo- } \\
\text { Rubinstein } \\
\text { technique) }\end{array}$ & $\begin{array}{l}M=69,7 \\
S D=12,5\end{array}$ & $\begin{array}{l}M=54,3 \\
S D=16,6\end{array}$ & $\begin{array}{c}\mathrm{F}_{\text {kpит }}=2,14 \\
\mathrm{p}<0,05\end{array}$ \\
\hline 2 & $\begin{array}{l}\text { Представления } \\
\text { субьекта об уни- } \\
\text { кальности, отличии } \\
\text { от окружающих } \\
\text { Individuals' ideas } \\
\text { about their unique } \\
\text { distinguishing } \\
\text { features }\end{array}$ & $\begin{array}{l}M=9,6 \\
S D=2,4\end{array}$ & $\begin{array}{l}M=9,1 \\
S D=2,2\end{array}$ & $\begin{array}{c}F_{\text {крит }}=0,49 ; \\
p>0,21 \\
\text { (не значимы) } \\
\text { (not } \\
\text { significant) }\end{array}$ \\
\hline
\end{tabular}




\begin{tabular}{|c|c|c|c|c|}
\hline \multirow[b]{2}{*}{$\begin{array}{l}\text { № } \pi / \Pi \\
\text { No. }\end{array}$} & \multirow[b]{2}{*}{$\begin{array}{l}\text { Измеряемые } \\
\text { показатели } \\
\text { Measured } \\
\text { characteristics }\end{array}$} & \multicolumn{2}{|c|}{$\begin{array}{c}\text { Комичественные } \\
\text { характеристики } \\
\text { Quantitative characteristics }\end{array}$} & \multirow{2}{*}{$\begin{array}{l}\text { Значения } \\
\text { статис- } \\
\text { тической } \\
\text { оценки } \\
\text { размичий } \\
\text { Statistical } \\
\text { differences }\end{array}$} \\
\hline & & $\begin{array}{c}\text { Ао преАъяв- } \\
\text { ления } \\
\text { информации } \\
\text { Before } \\
\text { presentation } \\
\text { of information }\end{array}$ & $\begin{array}{c}\text { После за- } \\
\text { вершения } \\
\text { предъявления } \\
\text { After pre- } \\
\text { sentation of } \\
\text { information }\end{array}$ & \\
\hline 3 & $\begin{array}{l}\text { Представления } \\
\text { субъекта о ком- } \\
\text { петентности } \\
\text { и эдрфрективно- } \\
\text { сти социального } \\
\text { взаимодействия } \\
\text { Individuals' ideas } \\
\text { about their com- } \\
\text { petence and ef- } \\
\text { ficiency in social } \\
\text { interactions }\end{array}$ & $\begin{array}{l}M=12,3 \\
S D=2,7\end{array}$ & $\begin{array}{l}M=10,7 \\
S D=2,9\end{array}$ & $\begin{array}{c}\mathrm{F}_{\text {крит }}=2,18 ; \\
\mathrm{p}<0,05 \\
\text { (значимы) } \\
\text { (significant) }\end{array}$ \\
\hline 4 & $\begin{array}{l}\text { Представления } \\
\text { субъекта о соот- } \\
\text { ветствии социаль- } \\
\text { ным ролям } \\
\text { Individuals' ideas } \\
\text { about their corre- } \\
\text { spondence to social } \\
\text { roles }\end{array}$ & $\begin{array}{l}M=13,7 \\
S D=3,1\end{array}$ & $\begin{array}{c}M=12,5 \\
S D=2,9\end{array}$ & $\begin{array}{c}\mathrm{F}_{\text {крит }}=2,55 ; \\
p<0,05 \\
\text { (значимы) } \\
\text { (significant) }\end{array}$ \\
\hline 5 & $\begin{array}{l}\text { Представления } \\
\text { субъекта о пол- } \\
\text { держке, помощи } \\
\text { окружающих } \\
\text { Individuals' ideas } \\
\text { about support and } \\
\text { help of others }\end{array}$ & $\begin{array}{l}M=10,4 \\
S D=3,3\end{array}$ & $\begin{array}{l}M=10,6 \\
S D=3,7\end{array}$ & $\begin{array}{c}\mathrm{F}_{\text {крит }}=0,57 ; \\
\mathrm{p}>0,55 \\
\text { (не значимы) } \\
\text { (not } \\
\text { significant) }\end{array}$ \\
\hline
\end{tabular}

Примечание: $M$ - среднее значение; SD-стандартное отклонение; $F_{\text {крит }}$ - критерий Фишера, отражающий величину различия между показателями; $p$-показатель статистической значимости; значения показателей округлены до одного знака после запятой.

Note: $M$ - mean score; $S D$-standard deviation; $F_{c r i t}-$ Fisher criterion; $p$-statistical significance; values are 
rounded down to the first digit after the comma.

Дисперсионный анализ показателей самооценки выявил статистически значимое снижение ее уровня под влиянием Я-релевантной информации $\left(\mathrm{F}_{\text {крит }}=(6,112)=2,14 ; \mathrm{p}<0,05\right)$. В значениях шкалы снижение составило в среднем 10 пунктов и фактически не являлось критичным.

Установлено статистически значимое снижение определенности представлений о компетентности и эффективности социального взаимодействия $\left(\mathrm{F}_{\text {крит }}=(8,119)=2,18 ; \mathrm{p}<0,05\right)$ и представлений о соответствии социальным ролям $\left(\mathrm{F}_{\text {крит }}=(8,119)=2,55 ; \mathrm{p}<0,05\right)$. Представление об уникальности и непохожести на окружающих изменялось, но статистически значимого уровня не достигло ( $p>0,25)$.

Стратегии поведения в случае несоответствия Я-релевантной информации представлениям субъекта о себе изучались посредством анализа результатов интервьюирования.

Установлены три типичные стратегии реагирования на несоответствующую представлениям Я-релевантную информацию: а) уточнение информации (83\% опрошенных - «уточнить подробности», «разобраться», «выяснить»); б) поиск источника негативной информации (62 \% опрошенных - «подойти к этому человеку», «спросить зачем», «поговорить, чтобы перестал»); в) действия по получению позитивной информации о себе (44\% опрошенных - «поговорить о хорошем», «поговорить с родителями», «повеселиться с друзьями»).

Определены две модели обращения за Я-релевантной информацией, условно названные нами «интровертивной» и «экстравертивной». Отличия между ними - в источниках информации, к которым обращается субъект для восстановления или изменения информации о себе.

Интровертированная модель основывается на «внутренних» источниках информации: опыте («так всегда говорят», «завидуют, вот и обсуждают») уверенности в себе («я себя знаю», «не верю, что я такая»), социальном сравнении («у других так же», «я ничем не отличаюсь»).

Экстравертированная модель поиска Я-релевантной информации использует «внешние» источники информации. С их помощью субъект проверяет негативную либо искажающую информацию («все знают, что я не такая», «никто в это не поверит»), ищет источники информации («спрошу, кто это говорит», «узнаю, откуда он это взял»).

\section{Обсуждение результатов}

Исследование показало, что Я-релевантная информация извлекается из социальной информации посредством оценки ее формальной 
и содержательной составляющих. При селекции информации на Я-релевантную и Я-нерелевантную испытуемые руководствуются признаками, указывающими на отношение информации к ним лично. Проведенный нами контент-анализ самоописаний позволил выделить наиболее часто используемые.

Первая группа признаков представляет собой коммуникативные маркеры, которые содержат: а) прямое указание на субъекта и его социальные признаки (имя, внешность, социальную роль); б) косвенное указание - обращение к субъекту в вербальной (например, формулы приветствия) и невербальной (паралингвистические) формах.

Вторая группа признаков определяется содержанием информации. Определено, что Я-релевантной испытуемые считают информацию, связанную с: а) потребностями, б) выполняемыми или планируемыми действиями, а также в) объектами или субъектами, которые субъект ассоциирует с собой. В ходе исследования ими выступали друзья, родственники, имущество - например, телефон, одежда и пр. Показано, что информация об искажении потребности (угрозы) рассматривается в качестве Я-релевантной.

По-видимому, коммуникативные маркеры и содержание информации выступают наиболее очевидными признаками, получая которые субъект атрибутирует принадлежность информации к себе. При этом их значение в распознавании может варьироваться. В проведенном нами исследовании основную роль играли маркеры коммуникации. Так, наличие в информации имени, указания на социальный статус или черты внешности приводило обследуемых к выводу об отношении информации к ним лично. Содержание информации лишь дополняло маркеры, усиливая убежденность обследуемых в принадлежности информации к ним. Однако наличие маркеров может не играть ведущей роли. Зачастую информация, предназначенная неопределенному адресату, атрибутируется как Я-релевантная, если она связана с потребностями субъекта. К примеру, сообщает об угрозе или невозможности их удовлетворения.

В целом, в исследовании нашло подтверждение то, что субъект чувствителен к информации, ассоциируемой с ним. Я-релевантная информация воспринимается быстрее и точнее, сохраняется дольше.

Я-релевантная информация способствует изменению представлений субъекта о себе. В исследовании изучалось влияние информации негативного и заведомо искажающего характера на представления субъекта о себе. Статистическая обработка результатов показала, что негативная Я-релевантная информация снижает самооценку, а искажающая информация ухудшает точность самопредставлений. Выявленные статистические закономерности согласуются с описанными фактами влияния Я-релевантной информации на самооценку и самоуважение субъекта [33]. Однако полученные результаты дополняют их, поскольку показывают, какие именно представления субъекта 


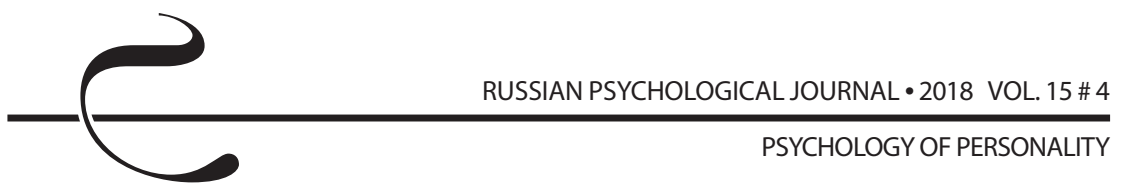

о себе модифицируются негативной Я-релевантной информацией.

Нами зафиксировано статистически значимое изменение двух разновидностей представлений: о компетентности и эффективности собственных действий и представление о выполнении социальной роли. Эти представления искажались следующим образом. Представление о собственной компетентности и готовности к эффективным действиям преобразовывалось в представление о неготовности действовать, необходимость в поддержке и помощи. Наконец, представление о поддержке окружающих искажалось настолько, что выражало изоляцию, отчуждение и отсутствие помощи.

Конечно, описанные нами искажения представлений имели реактивный характер - вызывающие их стимулы были заданы условиями эксперимента. Вместе с тем даже на краткий промежуток времени Я-релевантная информация трансформировала имеющиеся у субъекта представления о себе. Исходя из этого можно полагать, что влияние социальной информации и ее Я-релевантных составляющих на представления субъекта о себе недооценено и нуждается в более глубоком и систематизированном изучении.

Полученные результаты расширяют представление о компенсации самооценки, высказанные L. A. Rudman c соавторами [34], показывая, что угрозы искажения знания субъекта о себе также стимулируют к их восстановлению. В частности, несоответствующая Я-релевантная информация стимулирует поиск новой информации. В ходе исследования нами была установлена связь между несоответствующей Я-релевантной информацией, ее значимостью для субъекта и усилиями по ее верификации. На основе контент-анализа высказываний установлено, что негативная Я-релевантная информация стимулирует субъекта к поиску новой информации. В ходе эксперимента испытуемые посредством поиска стремились устранить несоответствия между имеющимся представлением и содержащимся в информации. Подчеркнем, что готовность искать информацию статистически зависит не только от уровня искажения представлений, но и опосредовалось несколькими внешними переменными. Выявленные в исследовании интровертированная и экстравертированные модели поиска Я-релевантной информации, по-видимому, не являются строго дифференцированными. В ходе эксперимента обследуемые комбинировали действия, которые мы относили к разным моделям. Так, наиболее часто сочетались действия по социальному сравнению и верификации информации, отнесенные нами к разным моделям. Конкретизация описанных моделей, оценка их способности представлять Я-релевантную информацию нуждаются в дальнейшей разработке.

Изучение моделей поведения участников эксперимента выявило три ведущие цели поиска информации: а) уточнение ранее полученной информации; б) поиск позитивной Я-релевантной информации для дополнения негативной; 
в) опровержение негативной Я-релевантной информации. Как правило, они комбинировались друг с другом - т. е. субъект стремился уточнять, а затем опровергать, либо уточнять и дополнять. Интересно, что в стратегии опровержения объектом воздействия выступал источник негативной информации. Обследуемые стремились получить объяснения, добиться извинений или прекратить распространение информации. Стратегия поиска позитивной информации предполагала обращение к друзьям, родственникам и не затрагивала объект негативной информации.

\section{Заключение}

Представленное в статье обсуждение теоретических идей, результатов эмпирических исследований указывает на роль Я-релевантной информации в формировании представления субъекта о себе. Она представляет собой часть информации, получаемой субъектом в ходе социального взаимодействия, включает мнения окружающих людей о субъекте и оценке его деятельности. Восприятие и интерпретация Я-релевантной информации имеют признаки атрибутивного процесса и зависят от социально-перцептивных и когнитивных способностей субъекта. В результате проведенного авторами эмпирического исследования установлено, что Я-релевантная информация эксплицируется из потока социальной информации благодаря признакам, позволяющим субъекту соотнести ее с собой. Ими выступают прямые и косвенные указания на субъект и его социальные характеристики, а также содержание информации, релевантное состоянию, действиям субъекта, его отношениям с окружающими.

Я-релевантная информация связана с представлениями субъекта о себе. Она влияет на его самооценку, обуславливает конкретность представлений о собственной компетентности и способности выполнять социальные роли. Негативная социальная информация влияет на представление субъекта о себе, искажает самоотношение, вторгается в самооценку, изменяя ее критерии и стандарты. Кроме того, несоответствующая представлениям субъекта о себе Я-релевантная информация побуждает субъекта к поиску дополнительной информации о себе, выражаясь в действиях по социальному сравнению, обращениям к окружающим за уточнением и верификацией информации.

В свете полученных результатов, дальнейшие исследования процессов и механизма изменения представлений субъекта о себе под влиянием Я-релевантной информации представляются продуктивными и целесообразными.

\section{Благодарности}

Работа выполнена за счет гранта Российского научного фонда (проект № 17-18-01278).

\section{Acknowledgments}

Supported by the Russian Science Foundation grant 17-18-01278. 


\section{Литература}

1. Smith, E.R., Queller, S. Mental Representations // Blackwell Handbook of Social Psychology: Intraindividual Processes. USA: Wiley-Blackwell, 2007. P. 111-133. DOI: $10.1002 / 9780470998519 . c h 6$

2. Леонов Н. И., Главатских М. М. Психология социального мира. Ижевск: Lingua Socialis, 2006. 132 c.

3. Higgins E. T, Bargh J. A. Social Cognition and Social Perception // Annual Review of Psychology. 1987. Vol. 38. P. 369-425. DOI: $10.1146 /$ annurev. psych.38.1.369

4. Gergen K. J. The concept of self. New York: Holt, Rinehart and Winston, 1971.

5. Leary M. The Self as a Source of Relational Difficulties // Self and Identity. 2002. Vol. 1, Issue 2. P. 137-142. DOI: $10.1080 / 152988602317319311$

6. Markus H. R., Kitayama S. Culture and the self: Implications for cognition, emotion, and motivation // Psychological Review. 1991. Vol. 98 (2). P. 224-253. DOI: $10.1037 / 0033-295 \times .98 .2 .224$

7. Klein S. B., Gangi C. E., Lax M. L. Memory and Self-knowledge in Young Adults with ADHD // Self and Identity. 2011. Vol. 10, Issue 2. P. 213-230. DOI: 10.1080/15298861003741604

8. Cheek N. N., Norem J. K. Holistic thinkers anchor less: Exploring the roles of self-construal and thinking styles in anchoring susceptibility // Personality and Individual Differences. 2017. Vol. 115. P. 174-176. DOI: 10.1016/j. paid.2016.01.034

9. Courage M. L., Howe M. L. Autobiographical Memory: Individual Differences and Developmental Course // Handbook of Individual Differences in Cognition. USA: Springer, 2010. P. 403-417. DOI: 10.1007/978-1-4419-1210-7 24

10. Park J., Uchida Y., Kitayama S. Cultural variation in implicit independence: An extension of Kitayama et al. // International Journal of Psychology. 2015. Vol. 51, Issue 4. P. 269-278. DOI: 10.1002/ijop.12157

11. Triandis H. C. Individualism-Collectivism and Personality // Journal of Personality. 2001. Vol. 69, Issue 6. P. 907-924. DOI: 10.1111/1467-6494.696169

12. Amiot C. E., de la Sablonniere R., Smith L. G. E., Smith J. R. Capturing Changes in Social Identities over Time and How They Become Part of the Self-concept // Social and Personality Psychology Compass. 2015. Vol. 9, Issue 4. P. 171-187. DOI: $10.1111 / \mathrm{spc} 3.12169$

13. Дорфман Л.Я. Я-концепция: дифференциация и интеграция // Интегральная индивидуальность, Я-концепция, личность / под ред. Л. Я. Дорфмана. М.: Смысл, 2004. С. 96-123.

14. Andersen S. M., Chen S. The relational self: An interpersonal social-cognitive theory // Psychological Review. 2002. Vol. 109 (4). P. 619-645. DOI: 10.1037/0033-295x.109.4.619 
15. Rudman L. A., Spencer S. J. The implicit self // Self and Identity. 2007. Vol. 6, Issue 2-3. P. 97-100. DOI: 10.1080/15298860601128271

16. Kihlstrom J. F., Cantor N. Mental Representations of the Self // Advances in Experimental Social Psychology. 1984. Vol. 17. P. 1-47. DOI: 10.1016/s00652601(08)60117-3

17. Klein S. B. "What is the Self?": Approaches to a Very Elusive Question // Social Cognition. 2012. Vol. 30, Special Issue: What is the Self? P. 363-366. DOI: $10.1521 /$ soco.2012.30.4.363

18. Klein S. B., Chan R. L., Loftus J. Independence of Episodic and Semantic SelfKnowledge: The Case from Autism // Social Cognition. 1999. Vol. 17, № 4. P. 413-436. DOI: $10.1521 /$ soco.1999.17.4.413

19. Markus $H$. Self-schemata and processing information about the self // Journal of Personality and Social Psychology. 1977. 35 (2). P. 63-78. DOI: 10.1037/0022-3514.35.2.63

20. Stein K. F., Corte C. Reconceptualizing causative factors and intervention strategies in the eating disorders: A shift from body image to self-concept impairments // Archives of Psychiatric Nursing. 2003. № 17 (2). P. 57-66. DOI: 10.1053 /apnu.2003.50000

21. Tskhay K. O., Rule N. O. Accuracy in Categorizing Perceptually Ambiguous Groups // Personality and Social Psychology Review. 2013. Vol. 17, Issue 1. P. 72-86. DOI: $10.1177 / 1088868312461308$

22. Hinkley K., Andersen S. M. The working self-concept in transference: Significant-other activation and self change // Journal of Personality and Social Psychology. 1996.Vol. 71 (6).P. 1279-1295.DOI: 10.1037/0022-3514.71.6.1279

23. McConnell A. R. The Multiple Self-Aspects Framework: Self-Concept Representation and Its Implications // Personality and Social Psychology Review. 2011. Vol. 15, Issue 1. P. 3-27. DOI: $10.1177 / 1088868310371101$

24. Gaertner L., Sedikides C., Luke M., O'Mara E. M., luzzini J., Jackson L. E., Wu Q. A motivational hierarchy within: Primacy of the individual self, relational self, or collective self? // Journal of Experimental Social Psychology. 2012. Vol. 48, Issue 5. P. 997-1013. DOI: 10.1016/j.jesp.2012.03.009

25. McConnell A. R., Rydell R. J., Brown C. M. On the experience of self-relevant feedback: How self-concept organization influences affective responses and self-evaluations // Journal of Experimental Social Psychology. 2009. Vol. 45, Issue 4. P. 695-707. DOI: 10.1016/j.jesp.2009.03.011

26. Azmat G., Iriberri N. The Provision of Relative Performance Feedback: An Analysis of Performance and Satisfaction // Journal of Economics \& Management Strategy. 2016. Vol. 25, Issue 1. P. 77-110. DOI: 10.1111/jems.12151

27. Hull J. G., Levy A. S. The organizational functions of the self: An alternative to the Duval and Wicklund Model of self-awareness // Journal of Personality and 
Social Psychology. 1979. 37 (5). P. 756-768. DOI: $10.1037 / 0022-3514.37 .5 .756$ 28. Kuiper N. A., Rogers T. B. Encoding of personal information: Self-other differences // Journal of Personality and Social Psychology. 1979. 37 (4). P.499-514. DOI: 10.1037/0022-3514.37.4.499

29. Hull J. G., Van Treuren R. R., Ashford S. J., et al. Self-consciousness and the processing of self-relevant information // Journal of Personality and Social Psychology. 1988. Vol. 54 (3). P. 452-465. DOI: 10.1037/0022-3514.54.3.452

30. Rogers T. B., Rogers P. J., Kuiper N. A. Evidence for the Self as a Cognitive Prototype: The "False Alarms Effect" // Personality and Social Psychology Bulletin. 1979. Vol. 5, Issue 1. P. 53-56. DOI: $10.1177 / 014616727900500111$

31. Злоказов К. В. Конструирование идентичности и криминализация личности: монография. Екатеринбург: Изд-во Уральского юридического института МВД России, 2017. 142 с.

32. Яньшин П. В. Практикум по клинической психологии. Методы исследования личности. СПб.: Питер, 2004. 336 с.

33. Baumeister R. F., Smart L., Boden J. M. Relation of threatened egotism to violence and aggression: The dark side of high self-esteem // Psychological Review. 1996. Vol. 103 (1). P. 5-33. DOI: 10.1037/0033-295x.103.1.5

34. Rudman L. A., Dohn M. C., Fairchild K. Implicit self-esteem compensation: Automatic threat defense // Journal of Personality and Social Psychology. 2007. Vol. 93 (5). P. 798-813. DOI: $10.1037 / 0022-3514.93 .5 .798$

\section{References}

1. Smith E. R., Queller S. Mental representations. In: Blackwell handbook of social psychology: Intraindividual processes. USA, Wiley-Blackwell, 2007, pp. 111-133. DOI: 10.1002/9780470998519.ch6

2. Leonov N. I., Glavatskikh M. M. Psikhologiya sotsial'nogo mira [Psychology of the social world]. Izhevsk, Lingua Socialis Publ., 2006. 132 p.

3. Higgins E. T, Bargh J. A. Social cognition and social perception. Annual Review of Psychology, 1987, V. 38, pp. 369-425. DOI: 10.1146/annurev.psych.38.1.369

4. Gergen K. J. The concept of self. New York: Holt, Rinehart and Winston, 1971.

5. Leary M. The self as a source of relational difficulties. Self and Identity, 2002, V. 1, Issue 2, pp. 137-142. DOI: 10.1080/152988602317319311

6. Markus H. R., Kitayama S. Culture and the self: Implications for cognition, emotion, and motivation. Psychological Review, 1991, V. 98 (2), pp. 224-253. DOI: 10.1037/0033-295x.98.2.224

7. Klein S. B., Gangi C. E., Lax M. L. Memory and self-knowledge in young adults with ADHD. Self and Identity, 2011, V. 10, Issue 2, pp. 213-230. DOI: $\underline{10.1080 / 15298861003741604}$ 
8. Cheek N. N., Norem J. K. Holistic thinkers anchor less: Exploring the roles of self-construal and thinking styles in anchoring susceptibility. Personality and Individual Differences, 2017,V. 115, pp. 174-176.DOI:10.1016/j.paid.2016.01.034

9. Courage M. L., Howe M. L. Autobiographical memory: Individual differences and developmental course. In: Handbook of individual differences in cognition. USA, Springer, 2010, pp. 403-417. DOI: 10.1007/978-1-4419-1210-7 24

10. Park J., Uchida Y., Kitayama S. Cultural variation in implicit independence: An extension of Kitayama et al. International Journal of Psychology, 2015, V. 51, Issue 4, pp. 269-278. DOI: 10.1002/ijop.12157

11. Triandis H. C. Individualism-collectivism and personality. Journal of Personality, 2001, V. 69, Issue 6, pp. 907-924. DOI: 10.1111/1467-6494.696169

12. Amiot C. E., de la Sablonniere R., Smith L. G. E., Smith J. R. Capturing changes in social identities over time and how they become part of the self-concept. Social and Personality Psychology Compass, 2015, V. 9, Issue 4, pp. 171-187. DOI: $10.1111 /$ spc3.12169

13. Dorfman L. Ya. Self-concept: Differentiation and integration. In: L. Ya. Dorfman (ed.) Integral'naya individual'nost', Ya-kontseptsiya, lichnost' [Integral individuality, self-concept, and personality]. Moscow, Smysl Publ., 2004, pp. $96-123$.

14. Andersen S. M., Chen S. The relational self: An interpersonal social-cognitive theory. Psychological Review, 2002, V. 109 (4), pp.619-645. DOI: 10.1037/0033295x.109.4.619

15. Rudman L. A., Spencer S. J. The implicit self. Self and Identity, 2007, V. 6, Issue 2-3, pp. 97-100. DOI: 10.1080/15298860601128271

16. Kihlstrom J. F., Cantor N. Mental representations of the self. Advances in Experimental Social Psychology, 1984, V. 17, pp. 1-47. DOI: 10.1016/s00652601(08)60117-3

17. Klein S. B. "What is the self?”: Approaches to a very elusive question. Social Cognition, 2012, V. 30, Special issue: What is the self? pp. 363-366. DOI: $10.1521 /$ soco.2012.30.4.363

18. Klein S. B., Chan R. L., Loftus J. Independence of episodic and semantic self-knowledge: The case from autism. Social Cognition, 1999, V. 17, no. 4, pp. 413-436. DOI: $10.1521 /$ soco.1999.17.4.413

19. Markus H. Self-schemata and processing information about the self. Journal of Personality and Social Psychology, 1977, 35 (2), pp. 63-78. DOI: 10.1037/0022-3514.35.2.63

20. Stein K. F., Corte C. Reconceptualizing causative factors and intervention strategies in the eating disorders: A shift from body image to self-concept impairments. Archives of Psychiatric Nursing, 2003, no. 17 (2), pp. 57-66. DOI: 10.1053/apnu.2003.50000 
21. Tskhay K. O., Rule N. O. Accuracy in categorizing perceptually ambiguous groups. Personality and Social Psychology Review, 2013, V. 17, Issue 1, pp. 72-86. DOI: $10.1177 / 1088868312461308$

22. Hinkley K., Andersen S. M. The working self-concept in transference: Significant-other activation and self change. Journal of Personality and Social Psychology, 1996, V. 71 (6), pp. 1279-1295. DOI: 10.1037/00223514.71.6.1279

23. McConnell A. R. The multiple self-aspects framework: Self-concept representation and its implications. Personality and Social Psychology Review, 2011, V. 15, Issue 1, pp. 3-27. DOI: 10.1177/1088868310371101

24. Gaertner L., Sedikides C., Luke M., O'Mara E. M., luzzini J., Jackson L. E., Wu Q. A motivational hierarchy within: Primacy of the individual self, relational self, or collective self? Journal of Experimental Social Psychology, 2012, V. 48, Issue 5, pp. 997-1013. DOI: 10.1016/j.jesp.2012.03.009

25. McConnell A. R., Rydell R. J., Brown C. M. On the experience of self-relevant feedback: How self-concept organization influences affective responses and self-evaluations. Journal of Experimental Social Psychology, 2009, V. 45, Issue 4, pp. 695-707. DOI: 10.1016/j.jesp.2009.03.011

26. Azmat G., Iriberri N.The provision of relative performance feedback: An analysis of performance and satisfaction. Journal of Economics \& Management Strategy, 2016, V. 25, Issue 1, pp. 77-110. DOI: 10.1111/jems.12151

27. Hull J. G., Levy A. S. The organizational functions of the self: An alternative to the Duval and Wicklund Model of self-awareness. Journal of Personality and Social Psychology, 1979, 37 (5), pp. 756-768. DOI: 10.1037/0022-3514.37.5.756

28. Kuiper N. A., Rogers T. B. Encoding of personal information: Self-other differences. Journal of Personality and Social Psychology, 1979, 37 (4), pp. 499-514. DOI: $10.1037 / 0022-3514.37 .4 .499$

29. Hull J. G., Van Treuren R. R., Ashford S. J., et al. Self-consciousness and the processing of self-relevant information. Journal of Personality and Social Psychology, 1988, V. 54 (3), pp. 452-465. DOI: $10.1037 / 0022-3514.54 .3 .452$

30. Rogers T. B., Rogers P. J., Kuiper N. A. Evidence for the self as a cognitive prototype: The "false alarms effect". Personality and Social Psychology Bulletin, 1979, V. 5, Issue 1, pp. 53-56. DOI: $10.1177 / 014616727900500111$

31. Zlokazov K. V. Konstruirovanie identichnosti i kriminalizatsiya lichnosti [Constructing identity and criminalization of personality]. Ekaterinburg, Ural Law Institute of the Ministry of Internal Affairs of the Russian Federation Publ., 2017. 142 p.

32. Yan'shin P. V. Praktikum po klinicheskoi psikhologii. Metody issledovaniya lichnosti [Tutorial on clinical psychology: Personality research methods]. St. Petersburg, Piter Publ., 2004. 336 p. 
33. Baumeister R. F., Smart L., Boden J. M. Relation of threatened egotism to violence and aggression: The dark side of high self-esteem. Psychological Review, 1996, V. 103 (1), pp. 5-33. DOI: 10.1037/0033-295x.103.1.5

34. Rudman L. A., Dohn M. C., Fairchild K. Implicit self-esteem compensation: Automatic threat defense. Journal of Personality and Social Psychology, 2007, V. 93 (5), pp. 798-813. DOI: $10.1037 / 0022-3514.93 .5 .798$ 